\title{
Effects of Slow-Mixing on the Coagulation Performance of Polyaluminum Chloride (PACI) ${ }^{*}$
}

\author{
ZHANG Zhongguo (张忠国) $)^{1, * *}$, LIU Dan (刘丹 ${ }^{1}$, HU Dandan (胡丹丹 $)^{2}$, LI Duo (李多) ${ }^{1}$, \\ REN Xiaojing (任晓晶) ${ }^{1, * *}$, CHENG Yanjun (程言君) ${ }^{1}$ and LUAN Zhaokun (奕兆坤) \\ Environmental Protection Research Institute of Light Industry, Beijing Academy of Science and Technology, Beijing \\ 100089, China \\ ${ }^{2}$ Beijing Academy of Science and Technology, Beijing 100089, China \\ ${ }^{3}$ State Key Laboratory of Environmental Aquatic Chemistry, Research Center for Eco-Environmental Sciences, \\ Chinese Academy of Sciences, Beijing 100085, China
}

\begin{abstract}
Conventional jar tests and on-line size monitoring were used to investigate the effects of slow-mixing intensity and duration on residual turbidity and floc size during charge neutralization coagulation and sweep flocculation with polyaluminum chloride. The compensatory effect of slow-mixing on coagulation performance following inadequate or excessive rapid-mixing was also examined. It is found that slow-mixing intensity has a more marked positive effect on charge neutralization coagulation than on sweep flocculation. The optimal root-meansquare velocity gradient, $G$, for slow-mixing is $15 \mathrm{~s}^{-1}$ for both coagulation mechanisms, and charge neutralization coagulation requires a longer slow-mixing duration. The optimal slow-mixing duration, based on residual turbidity, is longer than the time to form the largest mean flocs. The optimal product of $G$ and mixing duration, $G T$, for slow-mixing during charge neutralization coagulation (13500) are higher than that during sweep flocculation (4500) and both are less than the range of values recommended by the American Water Works Association (24000-84000). The optimal $G T$ value under various slow-mixing conditions increases with $G$. Appropriate extension of slow-mixing duration during charge neutralization coagulation can improve coagulation performance after an inadequate or excessive rapid-mixing duration, but during sweep flocculation, appropriate shortening of slow-mixing duration after an excessive rapid-mixing or appropriate extension of slow-mixing duration after an inadequate rapid-mixing is favorable. Keywords slow-mixing, polyaluminum chloride, charge neutralization coagulation, sweep flocculation, $G T$ value
\end{abstract}

\section{INTRODUCTION}

Coagulation is an important process that enhances separation in unit operations such as sedimentation, flotation and filtration, and is widely used for water and wastewater treatment. Many factors are involved in the coagulation process, including mixing conditions, coagulants, coagulation mechanisms and $\mathrm{pH}$ values.

There are generally two mixing regimes in the coagulation process, namely rapid-mixing and slowmixing. The primary function of slow-mixing is to keep particles in suspension so that collisions between particles occur [1]. Furthermore, slow-mixing can provide a velocity gradient for collisions between particles of similar size that are larger than $1 \mu \mathrm{m}[2,3]$. It is believed that eddies produced by mixing with similar size as particles can promote collisions between them and that larger eddies can only prevent particles from settling. High mixing intensities, characterized by the root-mean-square velocity gradient, $G$ [4], will produce small eddies. Therefore, an appropriate increase in $G$ is good for coagulation. However, eddies that are too small will induce floc breakup so it is very important to select proper $G$ value for slow-mixing. Of course, slow-mixing duration is also important for coagulation and the $G T$ value, the dimensionless product of $G$ and mixing duration, is usually recognized as an important design parameter for coagulation processes. The range of $G T$ values recommended by the American Water Works Association (AWWA) is $24000-84000$ and a typical slow-mixing duration is $20 \mathrm{~min}$ [5].

The size, strength and structure of flocs formed during coagulation are vital to subsequent separation units such as sedimentation, flotation and filtration. Many researchers [6-12] have found that, in addition to slow-mixing conditions, coagulants and coagulation mechanisms have significant effects on the size, strength and structure of flocs. This indicates that the effects of slow-mixing on coagulation are probably influenced by coagulants and coagulation mechanisms Most researches and conclusions about slow-mixing during coagulation are based on single-molecule inorganic salt coagulants, such as aluminum sulfate and iron chloride $[5,13,14]$. However, there has been a lack of systematic research into the effects of slow-mixing on coagulation with inorganic polymer coagulants such as polyaluminum chloride $(\mathrm{PACl})$ under different coagulation mechanisms. In fact, there are clear differences in molecular structure, formation conditions of hydrolyzed precipitates, morphology and properties of flocs between $\mathrm{PACl}$ and single-molecule inorganic salt coagulants $[8,15-18]$. PACl has gradually replaced

Received 2012-05-27, accepted 2012-08-06.

* Supported by the National High Technology Research and Development Program of China (2009AA063901), the Special Funds for Technological Development of Research Institutes from the Ministry of Science and Technology of China (2010EG111022, 2011EG111307), and the Budding Program (2011A-12-L) and the Program for Innovative Research Team (IG201204N) of Beijing Academy of Science and Technology.

** To whom correspondence should be addressed. E-mail: cn.zhang@163.com; jingjingmao0805@yahoo.com.cn 
single-molecule inorganic salt coagulants and has been widely applied because it has the advantages of efficient coagulation rates, low temperature dependence and wide $\mathrm{pH}$ applicability range [17-21].

In this study, based on conventional jar tests, the effects of slow-mixing on coagulation with $\mathrm{PACl}$ are investigated by measuring the residual turbidity of a kaolin suspension after coagulation-settlement and monitoring the variation in floc size during charge neutralization coagulation and sweep flocculation. In addition, the compensatory effect of slow-mixing on inadequate or excessive rapid-mixing durations is studied.

\section{MATERIALS AND METHODS}

\subsection{Experimental materials}

The PACl (Nanning Chemical Industry Co., Ltd, Nanning, China) was in powdered form, with a basicity $(\mathrm{OH} / \mathrm{Al})$ of 1.35 and an $\mathrm{Al}_{2} \mathrm{O}_{3}$ content of $30 \%$. The stock solution was obtained by dissolving $\mathrm{PACl}$ in deionized water, to an $\mathrm{Al}$ concentration of $2 \mathrm{~mol} \cdot \mathrm{L}^{-1}$. The fresh PACl solution for the tests had an $\mathrm{Al}$ concentration of $0.1 \mathrm{~mol} \cdot \mathrm{L}^{-1}$, obtained by diluting the stock solution one day before each batch of tests to avoid ageing and to maximize repeatability [22].

A stock solution of kaolin was prepared by dispersing $10 \mathrm{~g}$ kaolin in $5 \mathrm{~L}$ water, to give a concentration of $2 \mathrm{~g} \cdot \mathrm{L}^{-1}$. This could be used after rapid-mixing for $24 \mathrm{~h}$. The experimental suspensions were obtained by diluting the stock solution to a concentration of $100 \mathrm{mg} \cdot \mathrm{L}^{-\mathrm{P}}$, with a turbidity of 68 NTU. The kaolin was chemically pure, with a particle size distribution of $0.275-39.8$ $\mu \mathrm{m}$ and a mean particle size of $10.1 \mu \mathrm{m}$, produced by Beijing Xudong Chemical Plant, Beijing, China.

\subsection{Experimental methods}

\subsubsection{Jar test}

The conventional coagulation jar tests were conducted with a JTY-4 mixer made by Beijing Daiyuan Measurement \& Control Technology Development Center, Beijing, China. The coagulation vessel was a $1 \mathrm{~L}$ cylindrical container with an inner diameter of $105 \mathrm{~mm}$. The mixing was provided by a $50 \times 40 \mathrm{~mm}$ $(H \times W)$ flat rectangular blade, centrally located $15 \mathrm{~mm}$ above the base of the container. The rotation speed of the blade was adjustable.

The settling after coagulation took $10 \mathrm{~min}$ in all the tests. At the end of settling, a $10 \mathrm{~mL}$ supernatant sample was withdrawn with a syringe from $5 \mathrm{~mm}$ below the water level, to measure the residual turbidity.

According to a previous report [23], when the concentration of kaolin in simulated wastewater was $100 \mathrm{mg} \cdot \mathrm{L}^{-1}$ (68 NTU), the optimal PACl dosage during charge neutralization coagulation and sweep flocculation were 2.16 and $54.0 \mathrm{mg} \cdot \mathrm{L}^{-1}$ of $\mathrm{Al}$, respectively, with corresponding residual turbidities of 0.395 and 0.540 NTU, respectively. In this work, all charge neutralization coagulation and sweep flocculation experiments were carried out under their respective doses in the previous experiments [23], with a final $\mathrm{pH}$ of 8.0 and a temperature of $(14.0 \pm 1.0){ }^{\circ} \mathrm{C}$.

\subsubsection{Technology of on-line size monitoring}

An on-line size monitor using laser light scattering (Mastersizer 2000, Malvern Co., UK) was applied to monitor floc size during coagulation. The mixer used in the test was the JTY-4 mixer described above. A peristaltic pump (BT00-300M, Baoding Longer Precision Pump Co., Ltd., Baoding, China) was used, with a silicone tube of internal diameter $4.8 \mathrm{~mm}$.

A diagram of the on-line monitoring system is shown in Fig. 1. The kaolin suspension in the coagulation vessel was pumped into the sample cell of the laser particle size analyzer through the silicone tube for floc size measurement. The sample inlet was close to the inner wall of the coagulation vessel and located $34 \mathrm{~mm}$ below the water level. The outlet for the return sample from the sample cell was located just above the water level (to remove air bubbles) and was close

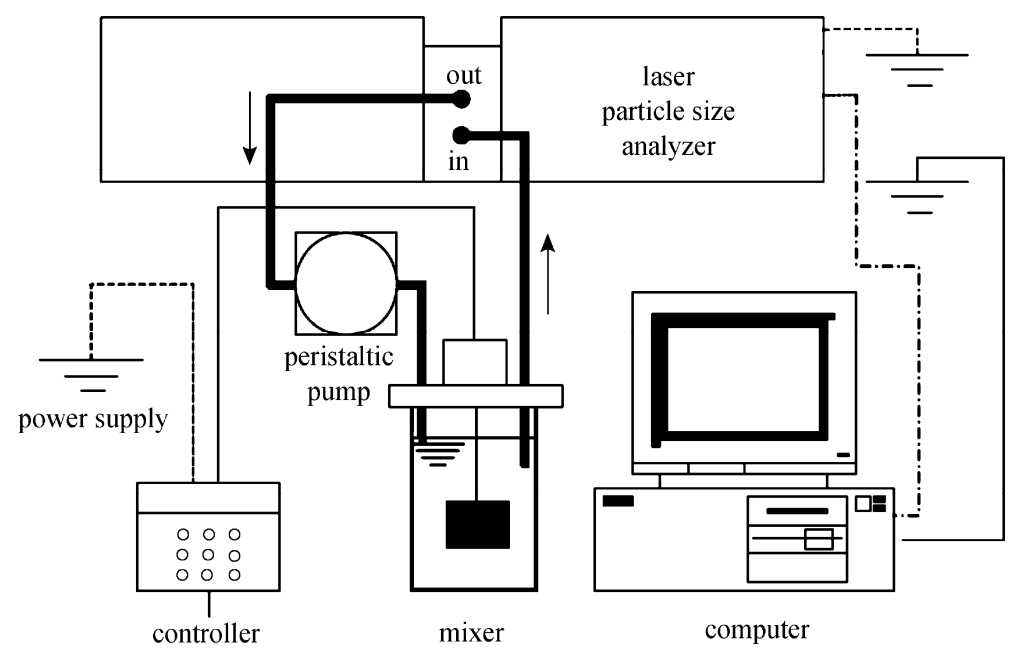

Figure 1 The on-line size monitor with laser light scattering 
to the inner wall of the coagulation vessel. The sample inlet and the return sample outlet were located at opposite ends (radial direction) of the coagulation vessel. The sample flux was $34 \mathrm{ml} \cdot \mathrm{min}^{-1}$. A higher flux would result in floc breakage [15], while a lower flux would result in floc settlement in the silicone tube and therefore cause a higher fluctuation of the particle size in the test result. The floc size was measured continuously, while the background measurement was carried out once before each set of experiments. The measurement duration was $30-50 \mathrm{~s}$ for the background measurement and 2 or $3 \mathrm{~s}$ for the sample measurement. The measurement interval was generally $10 \mathrm{~s}$.

\section{RESULTS AND DISCUSSION}

\subsection{Effect of slow-mixing on coagulation with PACl}

\subsubsection{Effect of slow-mixing on charge neutralization} coagulation

The effects of slow-mixing on the residual turbidity of charge neutralization coagulation with $\mathrm{PACl}$ were investigated at different slow-mixing intensities $\left(G=4,15\right.$ and $\left.38 \mathrm{~s}^{-1}\right)$ and slow-mixing durations of 1-60 min (rapid-mixing: $G=244 \mathrm{~s}^{-1}, t=3 \mathrm{~min}$ ). The results are shown in Fig. 2 (a). When the slow-mixing duration is within a certain range, such as $t<15 \mathrm{~min}$ at $G=15$ or $38 \mathrm{~s}^{-1}$, the residual turbidity decreases with slow-mixing duration. However, when the slow-mixing duration is longer, such as $t>15 \mathrm{~min}$ at $G=15$ or $38 \mathrm{~s}^{-1}$,

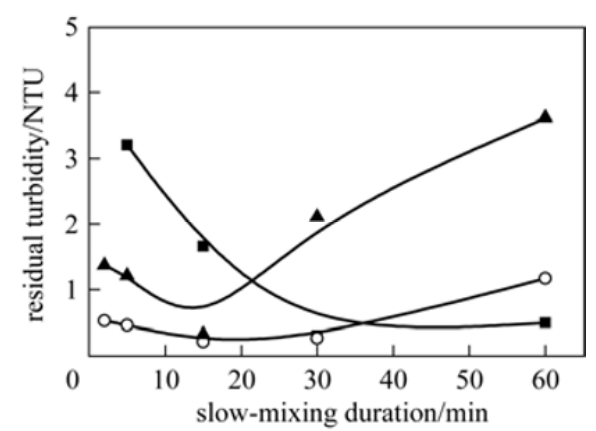

(a) Variation in residual turbidity

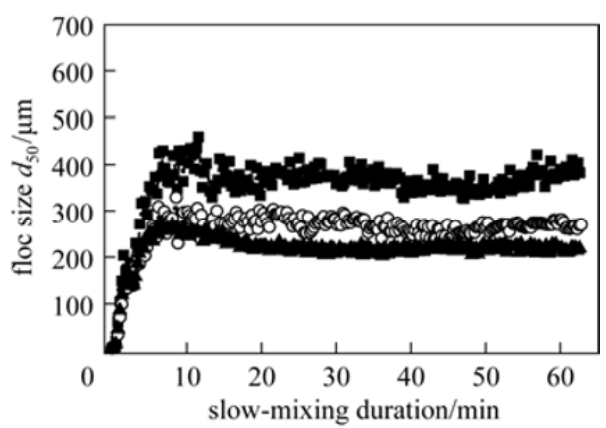

(b) Variation in floc size

Figure 2 Effects of slow-mixing on $\mathrm{PACl}$ charge neutralization coagulation (temperature: $15.0{ }^{\circ} \mathrm{C}$; kaolin: $100 \mathrm{mg} \cdot \mathrm{L}^{-1}$; PACl: $2.16 \mathrm{mg} \cdot \mathrm{L}^{-1}$ of Al; rapid-mixing: $G=244 \mathrm{~s}^{-1}, t=3 \mathrm{~min}$ ) slow-mixing intensity $G / \mathrm{s}^{-1}$ : 4 ; $\circ 15 ; \boldsymbol{\Delta} 38$ the residual turbidity increases with mixing duration, even at the $G$ value as low as $4 \mathrm{~s}^{-1}$. Furthermore, the increase in residual turbidity is more obvious when the mixing intensity is higher. It can also be seen that a higher slow-mixing intensity results in a shorter optimal slow-mixing duration. For example, the optimal slowixing duration is $15 \mathrm{~min}$ at $G=15 \mathrm{~s}^{-1}$, yet it is $30 \mathrm{~min}$ at $G=4 \mathrm{~s}^{-1}$. However, the $G T$ value is not constant, as discussed in more detail in the following section.

Figure 2 (a) shows that the optimal slow-mixing intensity during charge neutralization coagulation with $\mathrm{PACl}$ is $15 \mathrm{~s}^{-\mathrm{P}}$ and either higher or lower mixing intensity has a negative effect on flocculation. The variation in floc size during charge neutralization coagulation with $\mathrm{PACl}$ is shown in Fig. 2 (b). The floc size decreases with an increase in slow-mixing intensity, which is consistent with the results reported by others $[6,24,25]$. This means that a larger floc size does not imply better coagulation performance in the case of different slow-mixing intensities. By comparing Figs. 2 (a) and 2 (b), it also can be seen that the optimal slow-mixing duration is not simply the time to form the largest mean floc size but is longer, possibly because larger floc have a smaller fractional dimension and therefore a slower settling velocity [26-28].

\subsubsection{Effect of slow-mixing on sweep flocculation}

The effects of slow-mixing on the residual turbidity during sweep flocculation with $\mathrm{PACl}$ were also investigated under different slow-mixing intensities $\left(G=4,15\right.$ and $\left.38 \mathrm{~s}^{-1}\right)$ and slow-mixing durations of 1-60 min (rapid-mixing: $G=166 \mathrm{~s}^{-1}, t=3 \mathrm{~min}$ ). The results are shown in Fig. 3 (a). Similar to charge neutralization coagulation, for short slow-mixing durations, such as $t<10 \mathrm{~min}$ at $G=4 \mathrm{~s}^{-1}, t<5 \mathrm{~min}$ at $G=15$ $\mathrm{s}^{-1}$ or $t<3 \mathrm{~min}$ at $G=38 \mathrm{~s}^{-1}$, the residual turbidity decreases with time. Extending the mixing duration increases the residual turbidity. The results also show that higher slow-mixing intensities cause more obvious increase in residual turbidity. At the same time, higher slow-mixing intensities reduce the optimal slow-mixing duration. For example, the optimal slowmixing duration is $10 \mathrm{~min}$ at $G=4 \mathrm{~s}^{-1}$ but it is $3 \mathrm{~min}$ at $G=38 \mathrm{~s}^{-1}$. However, the $G T$ value also varies, consistent with that during charge neutralization coagulation.

Figure 3 (a) shows that the optimal slow-mixing intensity for sweep flocculation with $\mathrm{PACl}$ is $15 \mathrm{~s}^{-\mathrm{P}}$. At this slow-mixing intensity, the floc size is close to that at $4 \mathrm{~s}^{-1}$ but larger than that at $38 \mathrm{~s}^{-1}$ [Fig. 3 (b)]. This is generally consistent with the experimental results during charge neutralization coagulation. Fig. 3 shows that the optimal slow-mixing duration is longer than the time for forming the largest mean floc size.

Based on the above experimental results, neither charge neutralization coagulation nor sweep flocculation could reach their best coagulation performance at overly low or high slow-mixing intensities. Therefore, we conclude that coagulation performance is affected by both slow-mixing duration and intensity. In addition, it can be seen that the optimal coagulation performance 


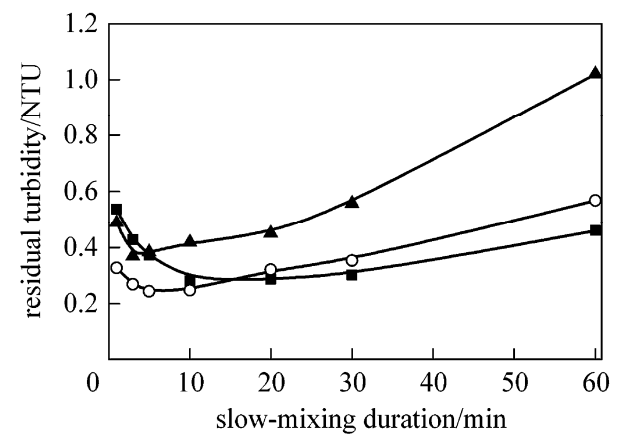

(a) Variation in residual turbidity

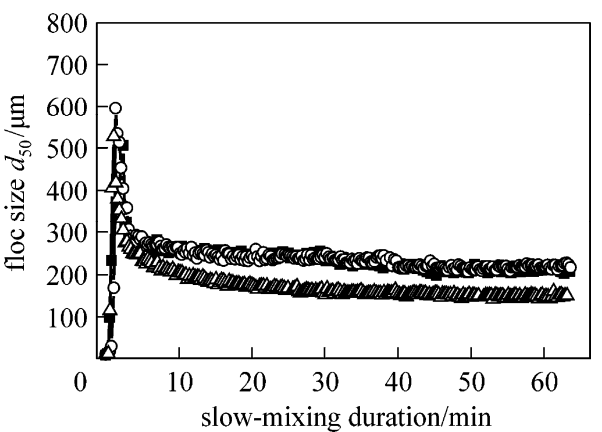

(b) Variation in floc size

Figure 3 Effects of slow-mixing on sweep flocculation with PACl (temperature: $13.5{ }^{\circ} \mathrm{C}$; kaolin: $100 \mathrm{mg} \cdot \mathrm{L}^{-1}$; $\mathrm{PACl}$ : 54.0 $\mathrm{mg} \cdot \mathrm{L}^{-1}$ of Al; rapid-mixing: $G=166 \mathrm{~s}^{-1}, t=3 \mathrm{~min}$ )

slow-mixing intensity $G / \mathrm{s}^{-1}$ : $\mathbf{a}$; $015 ; \boldsymbol{\Delta} 38$

could be obtained only with the optimal slow-mixing duration and the optimal slow-mixing intensity. At a lower slow-mixing intensity, some flocs will settle to the bottom of the coagulation vessel, which would reduce the collision rate between flocs. On the other hand, at a higher slow-mixing intensity, the flocs will breakup, which has a negative effect on the formation of large, compact flocs. Therefore, if the slow-mixing intensity is not optimal, it is difficult to obtain the best coagulation performance, even when the coagulation time is optimal. Taking Fig. 2 (a) (charge neutralization coagulation) as an example, at the optimal slow-mixing intensity of $15 \mathrm{~s}^{-1}$, the best coagulation performance is obtained at the optimal mixing duration of $15 \mathrm{~min}$, with a residual turbidity of 0.214 NTU. At a lower mixing intensity of $4 \mathrm{~s}^{-1}$, the best coagulation performance is obtained at an optimal mixing duration of $60 \mathrm{~min}$, with a residual turbidity of 0.496 NTU. At a higher slow-mixing intensity of $38 \mathrm{~s}^{-1}$, the best coagulation performance is obtained at an optimal mixing duration of $15 \mathrm{~min}$, with a residual turbidity of 0.323 NTU. Fig. 3 shows the same behavior during sweep flocculation. This indicates that during slowmixing, intensity is more important than mixing duration. It is also found that slow-mixing intensity has a greater positive effect on charge neutralization coagulation than on sweep flocculation with PACl. Furthermore, at the same slow-mixing intensity, charge neutralization coagulation requires a longer mixing duration than sweep flocculation. It is easy to understand this, based on Eq. (1).

Based on Figs. 2 (a) and 3 (a), the effect of $G$ on the optimal $G T$ value for slow-mixing can be obtained (Fig. 4). The optimal $G T$ value increases with $G$. For charge neutralization coagulation, the optimal $G T$ values at $G=4,15$ and $38 \mathrm{~s}^{-1}$ are 7200,13500 and 34200 , respectively. For sweep flocculation, the optimal $G T$ values at $G=4,15$ and $38 \mathrm{~s}^{-1}$ are 2400,4500 and 6840 , respectively. All the $G T$ values are smaller than the range recommended by the AWWA [5], except for the $G T$ value at $G=38 \mathrm{~s}^{-1}$ during charge neutralization coagulation. This seems to imply that $\mathrm{PACl}$ requires a smaller $G T$ value than conventional coagulants,

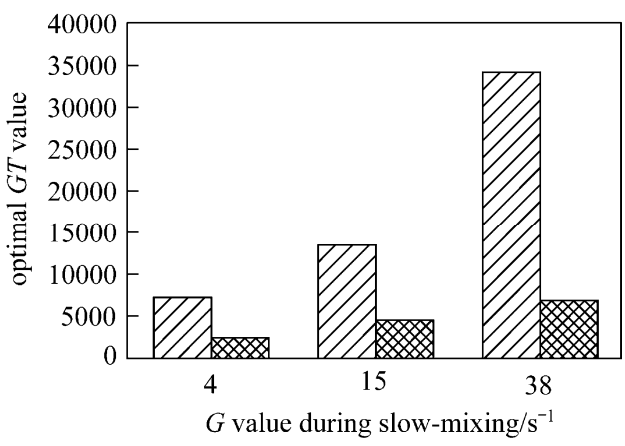

Figure 4 Effect of slow-mixing intensity on the optimal $G T$ value during slow-mixing (temperature: $14.0 \pm 1.0^{\circ} \mathrm{C}$; kaolin: $100 \mathrm{mg} \cdot \mathrm{L}^{-1}$; PACI: $2.16 \mathrm{mg} \cdot \mathrm{L}^{-1}$ of $\mathrm{Al}$ for charge neutralization coagulation and $54.0 \mathrm{mg} \cdot \mathrm{L}^{-1}$ of $\mathrm{Al}$ for sweep flocculation) WII charge neutralization coagulation; sweep flocculation

such as aluminum sulfate. The optimal $G T$ value during sweep flocculation is also smaller than that during charge neutralization coagulation for the same wastewater. This can be explained by Eq. (1), which is derived from the ortho-kinetic flocculation formula [29].

$$
G T=\frac{\pi}{4 \phi} \ln \left(\frac{N_{0}}{N_{t}}\right)
$$

where $N_{t}$ and $N_{0}$ are the floc number at flocculation time $t$ and the primary particle number, respectively, and $\phi$ is the particle or floc volume fraction. According to Eq. (1), for a given wastewater, the $G T$ value is constant when the same flocculation rate is obtained under the same flocculation conditions, except the $G$ value and slow-mixing duration. However, this is not the case, because of the effect of floc breakup.

\subsection{Compensatory effect of slow-mixing on rapid- mixing}

3.2.1 Compensatory effect of slow-mixing during charge neutralization coagulation

The compensatory effect of slow-mixing is shown in Fig. 5 for charge neutralization coagulation 


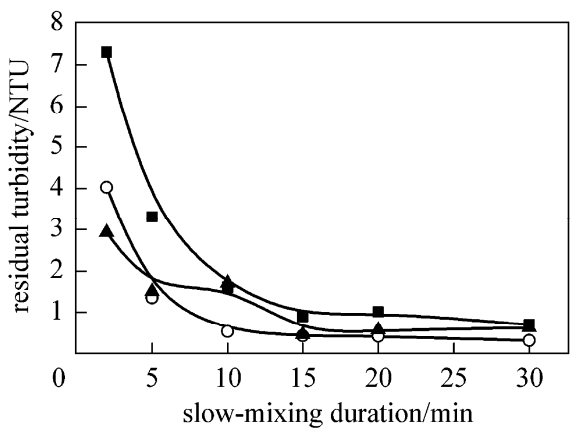

(a) Variation in residual turbidity

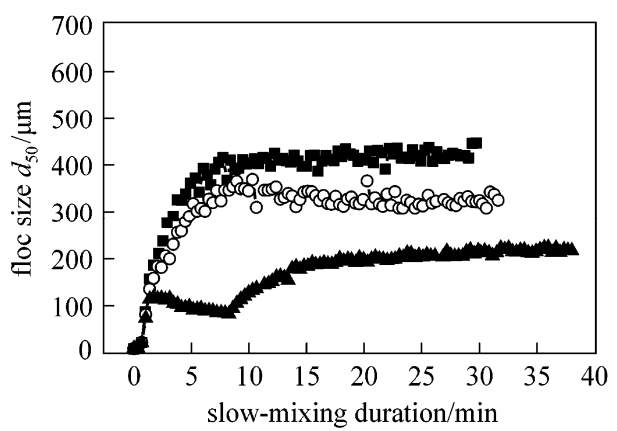

(b) Variation in floc size

Figure 5 Compensatory effects of slow-mixing on charge neutralization coagulation with PACl (temperature: $15.0{ }^{\circ} \mathrm{C}$; kaolin: $100 \mathrm{mg} \cdot \mathrm{L}^{-1}$; PACl: $2.16 \mathrm{mg} \cdot \mathrm{L}^{-1}$ of Al; slow-mixing intensity: $G=15 \mathrm{~s}^{-1}$, rapid-mixing intensity: $G=244 \mathrm{~s}^{-1}$ ) rapid-mixing duration/min: $\boldsymbol{\square} 1 ; \circ 2 ; \boldsymbol{\Delta} 8$

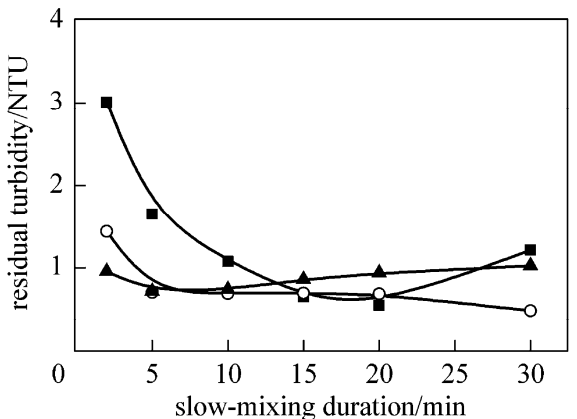

(a) Variation in residual turbidity

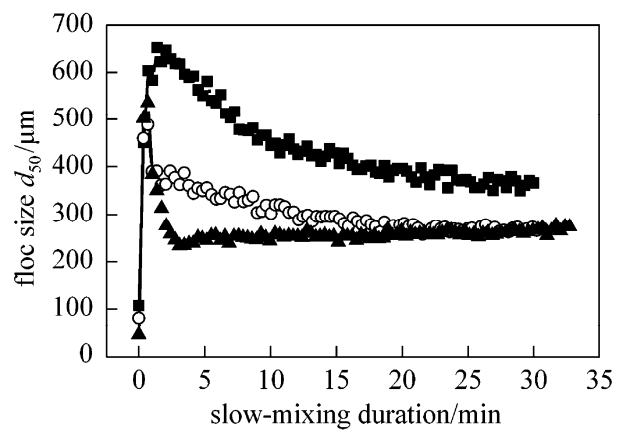

(b) Variation in floc size

Figure 6 Compensatory effects of slow-mixing on sweep coagulation with PACl (temperature: $13.5{ }^{\circ} \mathrm{C}$; $\mathrm{kaolin}: 100 \mathrm{mg} \cdot \mathrm{L}^{-1}$; PACl: $54.0 \mathrm{mg} \cdot \mathrm{L}^{-1}$ of Al; slow-mixing intensity: $G=15 \mathrm{~s}^{-1}$, rapid-mixing intensity: $G=244 \mathrm{~s}^{-1}$ )

rapid-mixing duration/s: - $10 ; \circ 50 ; \Delta 3 \mathrm{~min}$

in which rapid-mixing is inadequate or excessive, compared to the optimal rapid-mixing time of $2 \mathrm{~min}$ at $G=244 \mathrm{~s}^{-1}$. At any given slow-mixing duration over 5 min, the coagulation performance obtained at the optimal rapid-mixing duration of $2 \min \left(G=244 \mathrm{~s}^{-1}\right)$ is clearly superior to that at rapid-mixing durations of 1 or $8 \mathrm{~min}$. After a rapid-mixing duration of $2 \mathrm{~min}$, the residual turbidity of the kaolin suspension decreases to $0.53 \mathrm{NTU}$ at a slow-mixing duration of $10 \mathrm{~min}$, while the residual turbidity of the kaolin suspension with a slow-mixing duration of $20 \mathrm{~min}$ after rapid-mixing durations of 1 and $8 \mathrm{~min}$ decreases to 1.01 and 0.57 NTU, respectively. This indicates that for charge neutralization coagulation, prolonged slow-mixing could compensate for negative effects of inadequate or excessive rapid-mixing durations. However, the compensation is limited and does not attain the best performance under the optimal conditions for both rapid- and slow-mixing. Fig. 5 (b) shows that the flocs reach their largest size under the condition of 1 min rapid-mixing, while the residual turbidity is not the lowest. The reason for this is mainly the effect of the floc fractal dimension on settling rate $[27,28]$.

\subsubsection{Compensatory effect of slow-mixing during sweep flocculation}

Figure 6 shows the effect of slow-mixing when rapid-mixing is inadequate or excessive during sweep flocculation, where the optimal rapid-mixing duration is $50 \mathrm{~s}$ at $G=244 \mathrm{~s}^{-1}$. This shows that the effects of rapid-mixing duration on residual turbidities are relatively minor.

When the slow-mixing duration was in the range 5-10 min, the coagulation performance at a rapid-mixing duration of $3 \mathrm{~min}$ is similar to that at rapid-mixing duration of $50 \mathrm{~s}$, but when the slow-mixing duration is in the range $15^{-20} \mathrm{~min}$, the coagulation performance at a rapid-mixing duration of $10 \mathrm{~s}$ is similar to that at rapid-mixing duration of $50 \mathrm{~s}$. This indicates that, for sweep flocculation, when the rapid-mixing duration is too short, prolonging slow-mixing could compensate to some extent for the negative effects of insufficient rapid-mixing. However, when the rapid-mixing duration is too long, it appears that an appropriately shortened slow-mixing duration could attain superior coagulation performance. Overall, the coagulation performance at the optimal rapid-mixing duration is superior to those at inadequate or excessive rapid-mixing durations.

Figure 6 (b) shows the variation in floc size during sweep flocculation. As is the case in charge neutralization coagulation, and for the same reason, the flocs reach their largest sizes at a rapid-mixing duration of $1 \mathrm{~min}$. Furthermore, it can be seen from Figs. 5 
(a) and 6 (a) that the coagulation performance is improved with the increase of rapid-mixing duration when the slow-mixing duration is shorter than $5 \mathrm{~min}$. This seems to indicate that prolonging rapid-mixing duration can improve the coagulation performance of $\mathrm{PACl}$ when slow-mixing is insufficient.

\section{CONCLUSIONS}

There is an optimal slow-mixing intensity and duration for coagulation with $\mathrm{PACl}$. Higher or lower slow-mixing intensities and longer or shorter mixing durations produce inferior outcomes but intensity is more important than duration for coagulation with PACl. For a kaolin suspension of $100 \mathrm{mg} \cdot \mathrm{L}^{-1}$, the optimal $G$ value for slow-mixing is $15 \mathrm{~s}^{-1}$.

The slow-mixing duration required for the optimal coagulation performance decreases with increasing slow-mixing intensity but prolonged mixing duration clearly adversely affects coagulation. The slow-mixing intensity has a more marked positive effect on charge neutralization coagulation than on sweep flocculation and charge neutralization coagulation requires a longer slow-mixing duration. The optimal slow-mixing duration based on residual turbidity is longer than that required for forming the largest mean floc size. For a kaolin suspension of $100 \mathrm{mg} \cdot \mathrm{L}^{-1}$, the optimal slowmixing durations at $G=15 \mathrm{~s}^{-1}$ are $15 \mathrm{~min}$ and $5 \mathrm{~min}$ for charge neutralization coagulation and sweep flocculation, respectively. The optimal $G T$ value for slowmixing in charge neutralization coagulation (13500) is larger than that in sweep flocculation (4500). It is also found that the optimal $G T$ value increases with $G$.

Appropriate prolonging of the slow-mixing duration could improve coagulation performance in the case with inadequate or excessive rapid-mixing durations for charge neutralization coagulation. However, in the case of excessive rapid-mixing during sweep flocculation, shortening of the slow-mixing duration would be more favorable. The compensation by slowmixing for inadequate or excessive rapid-mixing is, however, limited and the best coagulation performance could be obtained only under optimal mixing conditions.

\section{REFERENCES}

1 Casson, L.W., Lawler, D.F., "Flocculation in turbulent flow: measurement and modelling of particle size distributions", $J$. $A W W A, \mathbf{8 2}$ (8), 54-68 (1990).

2 Han, M., Lawler, D.F., "The (relative) insignificance of $G$ in flocculation", J. AWWA, 84 (10), 79-91 (1992).

3 Lawler, D.F., "Theory of particle processes: Changes in size distribution in flocculation, sedimentation and filtration", In: Proceedings Workshop on Particle Counting and Characterization in Drinking Water Treatment, November, Johannesburg, South Africa (2000).

4 Camp, T.R., Stein, P.C., "Velocity gradients and internal work in fluid motion", Journal of the Boston Society of Civil Engineers, 30, 219-237 (1943).

5 American Water Works Association, "Coagulation and flocculation", In: Water Quality and Treatment: A Handbook of Community Water
Supplies, 5th edition, McGraw Hill, New York (2000).

6 Gregory, J., Dupont, V., "Properties of flocs produced by water treatment coagulants", Water Sci. Technol., 44 (10), 231-236 (2001).

7 Yukselen, M.A., Gregory, J., "The reversibility of floc breakage", International Journal of Mineral Processing, 73 (2-4), 251-259 (2004).

8 McCurdy, K., Carlson, K., Gregory, D., "Floc morphology and cyclic shearing recovery: comparison of alum and polyaluminum chloride coagulants", Water Research, 38 (2), 486-494 (2004).

9 Gregory, J., "Monitoring floc formation and breakage", Water Sci. Technol., 50 (12), 163-170 (2004).

10 Li, T., Zhu, Z., Wang, D.S., Yao, C.H., Tang, H.X., "Characterization of floc size, strength and structure under various coagulation mechanisms", Powder Technology, 168 (2), 104-110 (2006).

11 Jarvis, P., Jefferson, B., Parsons, S.A., "Floc structural characteristics using conventional coagulation for a high DOC, low alkalinity surface water source", Water Research, 40 (14), 2727-2737 (2006).

12 Wei, J.C., Gao, B.Y., Yue, Q.Y., Wang,Y., "Strength and regrowth properties of polyferric-polymer dual-coagulant flocs in surface water treatment", J. Hazard. Mater., 175 (1-3), 949-954 (2010).

13 Solomentseva, I., Bárány, S., Gregory, J., "The effect of mixing on stability and break-up of aggregates formed from aluminum sulfate hydrolysis products", Colloids and Surfaces A: Physicochemical and Engineering Aspects, 298 (1-2), 34-41 (2007).

14 Clark, M.M., Flora, J.R.V., "Floc restructuring in varied turbulent mixing", Journal of Colloid and Interface Science, 147 (2), 407-421(1991).

15 Jarvis, P., Jefferson, B., Parsons, S, "Breakage, regrowth, and fractal nature of natural organic matter flocs", Environ. Sci. Technol., 39 (7), 2307-2314 (2005).

16 Yukselen, M.A., Gregory, J., "The effect of rapid mixing on the break-up and reformation of flocs", J. Chem. Technol. Biotechnol., 79 (7), 782-788 (2004).

17 Zhao, C.W., Wang, J., Luan, Z.K., "Preparation of high concentration polyaluminum chloride with high Alc content by membrane distillation", Chin. J. Chem. Eng., 19 (1), 173-176 (2011).

18 Van Benschoten, J.E, Edzwald, J.K., "Chemical aspects of coagulation using aluminum salts-I. Hydrolytic reactions of alum and polyaluminum chloride", Wat. Res., 24 (12), 1519-1526 (1990).

19 Chen, Z.Y., Fan, B., Peng, X.J., Zhang, Z.Z., Fan, J.H., Luan, Z.K., "Evaluation of $\mathrm{Al}_{30}$ polynuclear species in polyaluminum solutions as coagulant for water treatment", Chemosphere, 64 (6), 912-918 (2006).

20 Takaara, T., Sano, D., Masago, Y., Omura, T., "Surface-retained organic matter of Microcystis aeruginosa inhibiting coagulation with polyaluminum chloride in drinking water treatment", Water Research, 44 (13), 3781-3786 (2010).

21 Nandy, T., Shastry, S., Pathe, P.P., Kaul, S.N., "Pre-treatment of currency printing ink wastewater through coagulation-flocculation process", Water, Air, \& Soil Pollution, 148 (1-4), 15-30 (2003).

22 Rossini, M., Garcia, G.J., Galluzzo, M., "Optimization of the coagulation-flocculation treatment: influence of rapid mix parameters", Water Research, 33 (8), 1817-1826 (1999).

23 Zhang, Z.G., Luan, Z.K., Zhao, Y., Cui, J.H., Chen, Z.Y., Li, Y.Z., "Breakage and regrowth of flocs coagulation with polyaluminum chloride (PACl)", Chin. J. Environ. Sci., 28 (2), 346-351 (2007). (in Chinese)

24 Parker, D. S., Kaufmann, W. J., Jenkins, D., "Floc breakup in turbulent flocculation processes", Jour. Sanitary Engineering Div., 98, 79-99 (1972).

25 Mühle, K., Domasch, K., "Stability of particle aggregates in flocculation with polymers", Chem. Eng. Progress, 29, 1-8 (1991).

26 Johnson, C.P., Li, X.Y., Logan, B., "Settling velocities of fractal aggregates”, Environ. Sci. Technol., 30 (6), 1911-1918 (1996).

27 Gregory, J., "The density of particle aggregates", Water Sci. Technol., 36 (4), 1-13 (1997).

28 Gregory, J., "The role of floc density in solid-liquid separation", Filtration \& Separation, 35 (4), 367-371 (1998).

29 Smoluchowski, M., "Versuch einer mathematischen theorie der koagulationskinetik kolloider lösungen", Z. Physik. Chem., 92, 129-168 (1917). 